\title{
FAKTOR PENGELOLAAN YANG BERPENGARUH TERHADAP PRODUKSI RUMPUT LAUT (Gracilaria verrucosa) DI TAMBAK TANAH SULFAT MASAM (STUDI KASUS DI KABUPATEN LUWU, PROVINSI SULAWESI SELATAN)
}

\begin{abstract}
Akhmad Mustafa dan Erna Ratnawati
ABSTRAK

Studi ini dilakukan untuk mengetahui faktor pengelolaan yang mempengaruhi produksi rumput laut di tambak tanah sulfat masam. Studi diawali dengan melihat kondisi tambak secara umum dan dilanjutkan dengan pengumpulan data secara acak dan berstruktur terhadap 30 petambak rumput laut di tambak tanah sulfat masam yang berlokasi di Desa Lamasi Pantai, Kecamatan Walenrang, Kabupaten Luwu. Pengumpulan data dilakukan pada bulan April 2002 dan November 2003. Data yang diperoleh dianalisis dengan statistik deskriptif dan regresi berganda dengan prosedur eleminasi langkah mundur. Hasil studi menunjukkan bahwa dengan menebar rumput laut rata-rata $1.499 \mathrm{~kg}$ basah/ha/th yang dipolikultur dengan nener bandeng 4.465 ekor/ha/th dan diberi pupuk urea, $\mathrm{KCl}$, dan kapur berturut-turut 40,14 , dan $32 \mathrm{~kg} / \mathrm{ha} / \mathrm{th}$ didapatkan produksi rumput laut $11.275 \mathrm{~kg}$ kering/ha/th di tambak tanah sulfat masam. Dari 11 variabel yang dikaji dalam studi ini menunjukkan bahwa hanya 7 variabel yang secara nyata dapat menentukan produksi rumput laut di tambak tanah sulfat masam yaitu berturut-turut dari yang terbesar pengaruhnya adalah dosis pupuk urea, luas tambak, pengalaman petambak, dosis pupuk $\mathrm{KCl}_{\text {, }}$ umur tambak, padat penebaran nener bandeng, dan dosis kapur. Produktivitas rumput laut di tambak tanah sulfat masam dapat ditingkatkan dengan menambah dosis pupuk urea, pupuk $\mathrm{KCl}$, dan kapur serta memperbanyak pengalaman petambak dan sebaliknya mengurangi luas tambak yang dikelola petambak dan menurunkan padat penebaran nener bandeng serta memulihkan kondisi tambak.
\end{abstract}

\begin{abstract}
Effects of management factors on seaweed (Gracilaria verrucosa) production in acid sulfate soils affected ponds (case study in Luwu Regency, South Sulawesi Province), by: Akhmad Mustafa and Erna Ratnawati

A study was conducted to understand the effects of management factors on seaweed production in acid sulfate soils affected ponds. The study begins observation of general pond condition 30 seaweed farmers in Lamasi Pantai Subdistrict, Luwu Regency were selected randomly to get culture performance. Collection of data was conducted in April 2002 and November 2003. Data was analyzed with descriptive statistics and multiple regressions with the backward elimination procedure. The results of study showed that fish farmers who stocked seaweed of $1,499 \mathrm{~kg}$ wet/hal year in the polyculture system with milkfish fry of 4,465 pieces/halyear resulted in the production of seaweed of $11,275 \mathrm{~kg}$ dry/ha/year. In the polyculture of seaweed and milkfish in acid sulfate soils affected ponds, fish farmers applied urea fertilizer, $\mathrm{KCl}$ fertilizer, and lime of 40,14 , and 32 $\mathrm{kg} / \mathrm{ha} /$ year, respectively. From 11 variables observed in this study, 7 variables of them can be usedthe to determine the production of seaweed in acid sulfate soils affected ponds. Dosage of urea fertilizer had highest effect followed by pond size, fish farmer experience, dosage $\mathrm{KCl}$ fertilizer, pond age, stocking density of milkfish fry, and dosage of lime. The productivity of seaweed in acid sulfate soils can be increased through addition of dosages of urea fertilizer, $\mathrm{KCl}$ fertilizer, lime, and fish farmers experience and the other hand through decreasing pond size managed by fish farmers, declining stocking density of milkfish fry, and recovering of pond condition.
\end{abstract}

KEYWORDS: management, acid sulfate soils, brackishwater pond, Gracilaria verrucosa, South Sulawesi

Peneliti pada Balai Riset Perikanan Budidaya Air Payau, Maros 


\section{PENDAHULUAN}

Tanah sulfat masam adalah nama umum yang diberikan kepada tanah yang mengandung besi sulfida atau pirit (Sammut \& Rebecca, 2000). Pirit ini terbentuk karena adanya besi dan bahan organik dari tanah serta adanya sulfat dari air laut yang diubah menjadi sulfida oleh mikroba. Oleh karena itu, tanah sulfat masam umumnya dijumpai di kawasan pesisir

Di Indonesia, tanah sulfat masam dapat mencapa Iuas 6,7 juta hektar dan diperkirakan 2,4 juta hektar di antaranya berasosiasi dengan tanah salin di kawasan pesisir. Di Sulawesi Selatan, tanah sulfat masam banyak dijumpai di Pantai Timur yang meliputi Kabupaten Sinjai, Bone, Wajo, Luwu, Luwu Utara, dan Luwu Timur, serta Kota Palopo (Mustafa et al., 2004). Tanah sulfat masam banyak dikonversi menjadi tambak, karena keberadaannya di kawasan pesisir yang memiliki sumber daya air untuk usaha budi daya tambak. Khusus di Kabupaten Luwu, tambak tanah sulfat masam diperkirakan mencapai luas 9.000 ha.

Tambak tanah sulfat masam yang baru atau belum dikelola tanahnya secara tepat memiliki kandungan unsur-unsur toksik tinggi dan ketersediaan fosfat rendah yang menyebabkan pertumbuhan udang dan ikan menjadi lambat dan sintasan menjadi rendah, sehingga tambak tanah sulfat masam tidak dapat berproduksi atau produktivitasnya rendah dan lebih lanjut menjadi tambak terlantar.

Rumput laut (Gracilaria verrucosa) adalah salah satu komoditas unggulan perikanan Provinsi Sulawesi Selatan yang mempunyai nilai ekonomis penting dan telah dibudidayakan di tambak. Telah dilaporkan oleh Daud et al. (1994) bahwa kualitas rumput laut dipengaruhi oleh kualitas tanah tambak. Tambak yang tidak lagi produktif untuk udang dan ikan dapat digunakan bagi usaha budi daya rumput laut, akan tetapi harus memenuhi persyaratan teknis dan biologis (Mubarak et al., 1990). Produktivitas tambak rumput laut masih dapat ditingkatkan melalui perbaikan teknik pengelolaan dalam budi daya maupun sarana irigasinya (Retnowati et al., 1995). Rumput laut juga telah dibudidayakan di tambak tanah sulfat masam. Namun demikian, belum banyak informasi yang diperoleh mengenai faktor pengelolaan dalam budi daya rumput laut di tambak tanah sulfat masam. Perbaikan tanah sulfat masam melalui teknik remediasi dapat meningkatkan produksi rumput laut sebanyak $250 \%$ dibanding tambak yang tidak diremediasi (Pantjara et al., 2003; Mustafa et al., 2004). Produksi rumput laut di tambak tanah sulfat masam dengan kedalaman air $50 \mathrm{~cm}$ lebih tinggi daripada kedalaman 25,75, dan $100 \mathrm{~cm}$ setelah dipelihara selama 45 hari (Hendrajat, 2004).
Faktor lain yang juga dianggap berpengaruh selain faktor kondisi tambak dan faktor teknik budi daya adalah status petambak. Rata-rata petambak rumput laut di tanah sulfat masam berumur 42 tahun, dengan masa pengalaman bertambak 19 tahun, dan tingkat pendidikan petambak rata-rata hanya tamat sekolah dasar. Walaupun tingkat pendidikan petambak relatif rendah, namun dengan pengalaman yang banyak memungkinkan dapat mengelola tambaknya secara lebih baik.

Kabupaten Luwu merupakan sentra pengembangan budi daya rumput laut di Provinsi Sulawesi Selatan (Anonim, 2003a). Kuantitas dan kualitas rumput laut yang dibudidayakan di tambak tanah sulfat masam di Kabupaten Luwu tergolong tinggi. Kualitas rumput laut dari Kabupaten Luwu merupakan salah satu yang terbaik di Indonesia (Anonim, 2003b). Teknik pengelolaan yang dilakukan petambak rumput laut di tambak tanah sulfat masam di Kabupaten Luwu bervariasi. Teknik pengelolaan yang berbeda dalam budi daya rumput laut berpengaruh terhadap produksi (Rasjid et al., 1993). Namun sejauh ini belum diketahui pengaruh teknik pengelolaan yang berbeda terhadap tingkat produksi yang dapat dicapai. Oleh karena itu, dilakukan studi untuk mengetahui pengaruh teknik pengelolaan yang diterapkan petambak dan faktor pengelolaan terhadap produksi rumput laut di tambak tanah sulfat masam

\section{BAHAN DAN METODE}

Data diperoleh dari responden petambak rumput laut di Desa Lamasi Pantai, Kecamatan Walenrang Kabupaten Luwu, Provinsi Sulawesi Selatan Sebanyak 30 responden petambak dipilih secara acak dari 200 petambak rumput laut di lahan sulfat masam di Desa Lamasi Pantai, diwawancarai secara langsung dengan menggunakan daftar kuisioner. Pengumpulan data dilakukan pada bulan April 2002 dan November 2003

Sebagai variabel tergantung (dependent variable) atau variabel respon dalam studi ini adalah produks rumput laut. Variabel bebas (independent variable) atau variabel prediktor dikelompokkan atas: (a) faktor status petambak yang meliputi variabel umur petambak, pendidikan petambak, dan pengalaman petambak; (b) faktor kondisi tambak yang meliputi variabel luas tambak dan umur tambak; dan (c) faktor teknik budi daya yang meliputi variabel padat penebaran rumput laut, padat penebaran nener bandeng, dosis pupuk urea, dosis pupuk $\mathrm{KCl}$, dosis kapur, dan frekuensi panen rumput laut. Mode persamaan regresi berganda yang diajukan adalah:

$$
Y=a+b_{1} X_{1}+b_{2} X_{2}+b_{3} X_{3}+\ldots \ldots+b_{n} X_{n}
$$


Statistik deskriptif digunakan untuk mendapatkan informasi umum dari data yang ada. Regresi berganda dengan variabel boneka (dummy variable) digunakan untuk menganalisis data dalam memprediksi besar variabel tergantung. Sebagai variabel boneka dari variabel bebas adalah pendidikan petambak. Dalam memilih persamaan regresi berganda "terbaik" maka digunakan prosedur eleminasi langkah mundur (the backward elemination procedure) (Draper \& Smith, 1992) dengan bantuan program SPSS (Statistical Product and Service Solution), di mana digunakan uji $F$ untuk menguji signifikansi model regresi dan uji t untuk menguji signifikansi koefisien regresi dari variabel bebas pada taraf signifikansi (á) sebesar 0,05.

\section{HASIL DAN BAHASAN}

Tambak tanah sulfat masam yang digunakan untuk budi daya rumput laut di Desa Lamasi Pantai, Kecamatan Walenrang, Kabupaten Luwu semuanya berasal dari lahan bekas hutan mangrove. Pada umumnya tambak hanya memiliki satu pintu air yang terbuat dari kayu. Walaupun telah tersedia saluran, namun belum jelas antara saluran pemasukan dan saluran pengeluaran air.

Sistem budi daya rumput laut yang dilakukan petambak adalah secara monokultur dan sebagian besar secara polikultur bersama dengan bandeng (Chanos chanos). Metode yang digunakan dalam budi daya rumput laut di tambak adalah metode tebar (broadcast method). Sumber air laut untuk budi daya tambak berasal dari Teluk Bone melalui Sungai Labonro-Bonro, sedangkan sumber air tawar dari Sungai Lamasi Pantai. Adanya sumber air tawar merupakan salah satu faktor yang mendukung keberhasilan budi daya rumput laut di Desa Lamasi Pantai. Menurut Sadhori (1989), rumput laut dalam pertumbuhannya memerlukan adanya sumber air tawar untuk menurunkan salinitas.

Di tambak tanah sulfat masam di Desa Lamasi Pantai, dengan rata-rata padat tebar rumput laut 1.499 $\mathrm{kg}$ basah/ha/th dapat diperoleh produksi rata-rata $11.275 \mathrm{~kg} \mathrm{kering} / \mathrm{ha} / \mathrm{th}$ (standar deviasi $4.756 \mathrm{~kg}$ kering/ha/th) dengan rata-rata frekuensi panen rumput laut mencapai 9 kali/th (Tabel 1). Produksi rumput laut ini lebih tinggi jika dibandingkan dengan produksi rumput laut petambak yang hanya mencapai 3.097 $\mathrm{kg} \mathrm{kering/ha/musim} \mathrm{(Retnowati} \mathrm{et} \mathrm{al.,} \mathrm{1995)} \mathrm{di}$ Kabupaten Takalar, yang juga merupakan sentra produksi rumput laut di Sulawesi Selatan selain Kabupaten Luwu. Rumput laut dibudidayakan di tambak tanah sulfat masam di Desa Lamasi Pantai melalui polikultur dengan bandeng. Padat penebaran nener bandeng yang diaplikasikan petambak rata-rata $4.465 \mathrm{ekor} / \mathrm{ha} / \mathrm{th}$. Nilai ini merupakan jumlah kumulatif nener bandeng yang ditebar selama satu tahun, karena petambak dapat menebar nener bandeng sampai 2 kali selama budi daya rumput laut. Petambak memanen bandengnya setelah mencapai ukuran 23 ekor/kg untuk mengurangi kemungkinan bandeng memakan rumput laut, dan selanjutnya ditebari lagi nener bandeng. Kehadiran bandeng dalam polikultur dengan rumput laut diharapkan dapat membersihkan rumput laut yang ditempeli oleh kelekap dan lumut. Dalam budi daya rumput laut biasanya ditebarkan bandeng dan udang yang dimaksudkan untuk mengurangi lumut di dalam tambak, karena keberadaan lumut akan menurunkan kualitas rumput laut kering (Retnowati et al., 1995). Bandeng akan memakan epifit yang menempel pada rumput laut dan akan meningkatkan kualitas rumput laut (Sammut et al., 2003). Selain itu, ikan bandeng diharapkan juga dapat menimbulkan gerakan air sehingga lumpur yang menempel pada rumput laut dapat terlepas. Akibat lebih lanjut adalah proses difusi unsur hara ke dalam rumput laut lebih meningkat, sehingga pertumbuhan rumput laut dapat lebih baik.

Dalam budi daya rumput laut di tambak tanah sulfat masam, sarana produksi tambak yang diaplikasikan petambak berupa pupuk urea, pupuk $\mathrm{KCl}$, dan kapur. Rata-rata dosis pupuk urea, pupuk $\mathrm{KCl}$, dan kapur yang digunakan berturut-turut 40,14 , dan $32 \mathrm{~kg} / \mathrm{ha} / \mathrm{th}$ (Tabel 1). Dosis sarana produksi tambak yang diaplikasikan ini termasuk rendah. Pupuk yang digunakan dalam budi daya rumput laut $d i$ tambak adalah campuran urea, TSP, dan ZA dengan perbandingan $1: 1: 1$ dan jumlahnya $20 \mathrm{~kg} / \mathrm{ha}$ setiap pemupukan (Mubarak et al., 1990). Jika berdasar pada pendapat Mubarak et al. (1990) bahwa pemupukan rumput laut di tambak dilakukan setiap 15 hari maka diperlukan total pupuk urea $160 \mathrm{~kg} / \mathrm{ha} / \mathrm{th}$. Selain itu hanya $10 \%$ petambak yang mengaplikasikan pupuk yang merupakan sumber $P$ seperti TSP di Desa Lamasi Pantai. Padahal $P$ merupakan unsur yang sangat rendah kandungannya dalam tanah sulfat masam, di samping ketersediaannya yang juga rendah karena terikat oleh $\mathrm{Fe}$ dan Al tanah. Sebaliknya $P$ merupakan unsur penting bagi semua aspek kehidupan terutama dalam transformasi energ metabolik (Kuhl, 1974). Unsur P juga merupakan penyusun ikatan pirofosfat dari ATP (adenosine trifosfat) yang kaya energi dan merupakan bahan bakar untuk semua kegiatan biokimia di dalam sel hidup serta merupakan penyusun sel yang penting (Noggle \& Fritz, 1986)

Gambaran petambak secara umum di Sulawesi Selatan, seperti dilaporkan oleh Padda (1986) bahwa petambak di Kabupaten Jeneponto, Sulawesi Selatan memiliki pengalaman rata-rata 19 tahun dengan pendidikan minimal tamat Sekolah Dasar dan telah 
Tabel 1. Rata-rata dan standar deviasi berbagai variabel dalam budi daya rumput laut di tambak tanah sulfat masam $(n=30)$

Table 1. Mean and standard deviation of some variables in seaweed culture in acid sulfate soils affected ponds $(n=30)$

\begin{tabular}{|c|c|c|}
\hline $\begin{array}{l}\text { Variabel } \\
\text { Variables }\end{array}$ & $\begin{array}{l}\text { Rata-rata } \\
\text { Mean }\end{array}$ & $\begin{array}{l}\text { Standar deviasi } \\
\text { Standard deviation }\end{array}$ \\
\hline $\begin{array}{l}\text { Produksi rumput laut }(\mathrm{kg} / \mathrm{ha} / \mathrm{th}) \\
\text { Seaweed production }(\mathrm{kg} / \mathrm{ha} / \text { year) }\end{array}$ & $11,274.90$ & $4,756.07$ \\
\hline $\begin{array}{l}\text { Dosis pupuk urea }(\mathrm{kg} / \mathrm{ha} / \mathrm{th}) \\
\text { Dosage of urea fertilizer }(\mathrm{kg} / \mathrm{ha} / \text { year) }\end{array}$ & 39.52 & 43.62 \\
\hline Luas tambak (Pond size) (ha) & 2.28 & 1.95 \\
\hline $\begin{array}{l}\text { Pengalaman petambak (th) } \\
\text { Fish farmer experience (year) }\end{array}$ & 18.63 & 11.30 \\
\hline $\begin{array}{l}\text { Dosis pupuk } \mathrm{KCl}(\mathrm{kg} / \mathrm{ha} / \mathrm{th}) \\
\text { Dosage of } \mathrm{KCl} \text { fertilizer }(\mathrm{kg} / \mathrm{ha} / \text { year) }\end{array}$ & 13.55 & 31.08 \\
\hline $\begin{array}{l}\text { Umur tambak (th) } \\
\text { Pond age (year) }\end{array}$ & 24.90 & 6.53 \\
\hline $\begin{array}{l}\text { Padat penebaran nener bandeng (ekor/ha/th) } \\
\text { Milkfish fry stocking density (pieces/ha/year) }\end{array}$ & $4,465.20$ & $3,663.84$ \\
\hline $\begin{array}{l}\text { Dosis kapur }(\mathrm{kg} / \mathrm{ha} / \mathrm{th}) \\
\text { Dosage of lime ( } \mathrm{kg} / \mathrm{ha} \text { /year) }\end{array}$ & 32.07 & 63.79 \\
\hline
\end{tabular}

berumur rata-rata 53 tahun. Sebanyak $81,28 \%$ petambak di Kabupaten Bulukumba, Takalar, dan Maros (Sulawesi Selatan) hanya tamat dari Sekolah Dasar (Hanafi, 1990).

Walaupun produksi rumput laut di tambak tanah sulfat masam relatif tinggi, namun masih ada peluang untuk meningkatkan produksi tersebut dengan mengetahui faktor pengelolaan (status petambak, kondisi tambak, dan teknik budi daya) dalam budi daya rumput laut yang dominan mempengaruhi produksi rumput laut. Di antara 11 variabel yang dikaji, ternyata variabel pendidikan petambak adalah variabel pertama yang tereliminasi (dikeluarkan) dari model regresi yang berarti pendidikan petambak merupakan faktor yang paling kecil pengaruhnya dalam menentukan produksi rumput laut di tambak tanah sulfat masam. Satu lagi faktor status petambak yang juga tereliminasi dari model regresi adalah variabel umur petambak yang tereliminasi setelah variabel pendidikan petambak, padat penebaran rumput laut, dan frekuensi panen rumput laut (Tabel 2). Dalam hal ini, dari faktor status petambak, hanya variabel pengalaman petambak yang mempengaruhi produksi rumput laut di tambak tanah sulfat masam. Pada umumnya, petambak tradisional melakukan perubahan pengelolaan dalam budi daya tambak hanya didasarkan pada pengalaman sebelumnya. Oleh karena itu, semakin banyak pengalaman petambak semakin baik teknik pengelolaan yang dilakukan dan pada akhirnya dapat meningkatkan produksi rumput laut.

Pada Tabel 2 terlihat bahwa padat penebaran rumput laut merupakan variabel kedua dari semua variabel atau variabel pertama dari faktor teknik budi daya yang tereliminasi dari model regresi. Hal ini menunjukkan bahwa padat penebaran rumput laut yang dilakukan petambak tidak lagi mempengaruhi produksi rumput laut di tambak tanah sulfat masam. Hal ini diduga karena padat penebaran rumput laut yang diterapkan petambak tidak terlalu jauh berbeda dengan penebaran yang telah dianjurkan. Seperti dikatakan oleh Mubarak et al. (1990) bahwa padat penebaran rumput laut yang optimal di tambak adalah $800-1.000 \mathrm{~kg}$ basah/ha. Demikian juga halnya variabel frekuensi panen yang tereliminasi dari model regresi. Hal ini menunjukkan bahwa frekuensi panen rumput laut yang dilakukan petambak ( 9 kali/th) tidak mempengaruhi produksi rumput laut di tambak tanah sulfat masam. Panen rumput laut di tambak yang baik adalah 4 bulan pertama dan selanjutnya setiap $40-$ 45 hari untuk mendapatkan kuantitas dan kualitas rumput laut yang tinggi (Mubarak et al., 1990). Dengan berdasar pada acuan tersebut, maka frekuensi panen rumput dapat dilakukan sampai $8 \mathrm{kali} / \mathrm{th}$ untuk mendapatkan kuantitas dan kualitas rumput laut yang tinggi, frekuensi panen ini tidak berbeda jauh dengan yang dilakukan petambak tanah sulfat masam. Juga telah dilaporkan oleh Retnowati et al. (1995) bahwa 
Tabel 2. Variabel yang dimasukkan dan variabel yang dikeluarkan dalam penentuan faktor pengelolaan budi daya rumput laut di tambak tanah sulfat masam ${ }^{*}$

Table 2. Variables entered and variables removed to determine of management factors in seaweed culture in acid sulfate soils affected ponds.

\begin{tabular}{|c|c|c|}
\hline Model & $\begin{array}{c}\text { Variabel yang dimasukkan } \\
\text { Variables entered }\end{array}$ & $\begin{array}{c}\text { Variabel yang dikeluarkan } \\
\text { Variables removed }\end{array}$ \\
\hline 1 & $\begin{array}{l}\text { Umur petambak (fish farmer age), pendidikan petambak (fish } \\
\text { farmer education), pengalaman petambak (fish farmer } \\
\text { experience), luas tambak (pond size), umur tambak (pond } \\
\text { age), padat penebaran rumput laut (seaweed stocking } \\
\text { density), padat penebaran nener bandeng (milkfish fry } \\
\text { stocking density), dosis pupuk urea (oosage of urea } \\
\text { fertilizer), dosis pupuk } \mathrm{KCl} \text { (dosage of } \mathrm{KCl} \text { fertilizer), dosis } \\
\text { kapur (dosage of lime), frekuensi panen rumput laut } \\
\text { (seaweed harvest frequency) }\end{array}$ & - \\
\hline 2 & - & $\begin{array}{l}\text { Pendidikan petambak } \\
\text { Fish farmer education }\end{array}$ \\
\hline 3 & - & $\begin{array}{l}\text { Penebaran rumput laut } \\
\text { Seaweed stocking density }\end{array}$ \\
\hline 4 & - & $\begin{array}{l}\text { Frekuensi panen rumput laut } \\
\text { Seaweed harvest frequency }\end{array}$ \\
\hline 5 & - & $\begin{array}{l}\text { Umur petambak } \\
\text { Fish farmer age }\end{array}$ \\
\hline
\end{tabular}

Keterangan (Note):

- Variabel tergantung (dependent variable): produksi rumput laut (seaweed production)

petambak rumput laut di Kabupaten Takalar, Sulawesi Selatan melakukan panen dengan frekuensi $6-7$ kali/ ha/musim.

Pada Lampiran 1 terlihat bahwa $\mathrm{R}^{2}$ yang disesuaikan (adjusted $\mathrm{R}^{2}$ ) tertinggi $(0,537)$ didapat pada model terakhir (Model 5), berarti akan semakin baik bagi model regresi, karena variabel bebas dapat menjelaskan variabel tergantung lebih besar. Dalam hal ini $53,7 \%$ produksi rumput laut di tambak tanah sulfat masam dapat dijelaskan oleh variabel dosis pupuk urea, luas tambak, pengalaman petambak, dosis pupuk $\mathrm{KCl}$, umur tambak, padat penebaran nener bandeng, dan dosis kapur, sedangkan sisanya $(46,3 \%)$ dijelaskan oleh faktor lain. Dari Lampiran 1 juga terlihat bahwa standar galat estimasi (standard error of estimate) terendah $(3.236,27 \mathrm{~kg} / \mathrm{ha} / \mathrm{th})$ dijumpai pada Model 5. Selain itu, karena standar galat estimasi lebih kecil dari standar deviasi produksi rumput laut yang besarnya $4.756,07 \mathrm{~kg} / \mathrm{ha} /$ th (Tabel 1), maka model regresi lebih baik dalam bertindak sebagai prediktor produksi rumput laut daripada ratarata produksi rumput laut itu sendiri. Selanjutnya dari hasil analisis ragam atau Uji F (Lampiran 2) menunjukkan Model 5 memiliki $F$ hitung sebesar 5,805 dan nilai $P$ sebesar 0,001 , maka model regresi dari Model 5 dapat digunakan untuk memprediksi produksi rumput laut di tambak tanah sulfat masam.

Pada Model 5 dari Lampiran 3 dapat dilihat konstanta dan koefisien regresi dari persamaan regresi yang terpilih dan selanjutnya akan digunakan untuk mempradiksi produksi rumput laut di tambak tanah sulfat masam. Variabel yang dominan berperan dalam menentukan produksi rumput laut di tambak tanah sulfat masam digambarkan dalam persamaan regresi sebagai berikut:

di mana:

$$
Y=14.293,13+109,53 X_{1}-1.839,80 X_{2}+218,26 X_{3}+87,31 X_{4}-275,98 X_{5}-0,49 X_{6}+20,45 X_{7}
$$

$Y=$ produksi rumput laut

$\mathrm{X}_{1}=$ dosis pupuk urea $(P=0,000)$

$X_{2}=$ luas tambak $(P=0,001)$
$X_{3}=$ pengalaman petambak $(P=0,001)$

$X_{4}=$ dosis pupuk $\mathrm{KCl}(P=0,005)$

$X_{5}=$ umur tambak $(P=0,012)$ 
$X_{6}=$ padat penebaran nener bandeng $(P=0,040)$

$X_{4}=$ dosis $\operatorname{kapur}(P=0,046)$

Konstanta sebesar 14.293,13 yang berarti produksi rumput laut dapat diprediksi mencapai $14.293,13 \mathrm{~kg}$ kering/ha/th walaupun tidak ada kontribusi dari faktor pengelolaan. Dari 11 variabel yang dikaji dalam studi ini, ternyata pupuk urea merupakan variabel yang paling berpengaruh dalam meningkatkan produksi rumput laut di tambak tanah sulfat masam. Koefisien regresi dari variabel dosis pupuk urea sebesar $+109,53$ yang berarti setiap penambahan dosis pupuk urea $1 \mathrm{~kg} / \mathrm{ha} / \mathrm{th}$ dapat meningkatkan (tanda +) produksi rumput laut sebesar $109,53 \mathrm{~kg}$ kering/ha/th di tambak tanah sulfat masam. Pupuk urea adalah sumber $\mathrm{N}$ dan telah diketahui bahwa $\mathrm{N}$ merupakan unsur hara makro bagi rumput laut yang berarti $\mathrm{N}$ dibutuhkan dalam jumlah besar bagi rumput laut. Nitrogen diperlukan untuk pertumbuhan dan produksi tanaman serta memainkan peranan penting dalam perkembangan dan fungsi protoplasma.

Variabel kedua yang berpengaruh terhadap produksi rumput laut adalah variabel luas tambak. Namun berbeda dengan pupuk urea yang apabila ditambahkan dapat meningkatkan produksi rumput laut, sebaliknya penambahan luas tambak justru menurunkan produktivitas tambak tanah sulfat masam untuk budi daya rumput laut. Hal ini dapat dimengerti bahwa semakin luas tambak yang dikelola oleh seorang petambak, maka semakin berkurang tingkat pengelolaan yang dilakukan karena petambak dibatasi oleh tenaga dan waktu serta kemungkinan dana. Dengan ukuran tambak yang lebih kecil cenderung petambak memaksimalkan penggunaan sumber daya tersebut untuk memperoleh hasil yang lebih baik dibandingkan dengan tambak yang lebih luas

Satu-satunya faktor status petambak yang beipengaruh terhadap produksi rumput laut di tambak tanah sulfat masam adalah variabel pengalaman petambak. Hal ini jelas terlihat pada koefisien regresi dari variabel pengalaman petambak yang bernilai $+218,16$ yang berarti seliap penambahan pengalaman 1 tahun dari petambak dapat meningkatkan produksi rumput laut $218,16 \mathrm{~kg}$ kering/ha/th. Seperti telah dijelaskan sebelumnya bahwa petambak pada umumnya melakukan perubahan pengelolaan berdasarkan pengalaman yang diperoleh sebelumnya. Oleh karena itu, semakin banyak pengalaman petambak maka produksi rumput laut dapat ditingkatkan. Pengalaman bertambak bukan hanya didapat selama melaksanakan pengelolaan tambak, tetapi juga dapat diperbanyak melalui pendidikan informal. Walaupun pendidikan formal petambak relatif rendah, tetapi dengan sarana dan prasarana yang tersedia berupa jalan maupun listrik (dapat menonton televisi dan mendengar radio) memungkinkan petambak dapat menerima informasi baru ataupun menerima inovasi terbaru. Pengalaman petambak juga dapat diperbanyak dengan mengikuti berbagai pelatihan atau sarasehan serta banyak mendapat penyuluhan terutama informasi mengenani budi daya rumput laut.

Seperti halnya pupuk urea, maka sarana produksi tambak lainnya seperti pupuk $\mathrm{KCl}$ dan kapur juga nyata dapat meningkatkan produksi rumput laut di tambak tanah sulfat masam sampai pada batas tertentu. Penambahan dosis pupuk $\mathrm{KCl} 1 \mathrm{~kg} / \mathrm{ha} / \mathrm{th}$ dapat meningkatkan produksi rumput laut sebanyak $87,31 \mathrm{~kg} \mathrm{kering} / \mathrm{ha} / \mathrm{th}$. Pupuk KCl merupakan sumber unsur hara $\mathrm{K}$ dan $\mathrm{Cl}$. Unsur hara $\mathrm{K}$ merupakan unsur hara makro yaitu unsur hara yang dibutuhkan dalam jumlah banyak oleh tanaman, sedangkan $\mathrm{Cl}$ adalah unsur hara mikro yang dibutuhkan oleh sistem kehidupan tanaman dalam jumlah sedikit. Khlor sangat dibutuhkan tanaman untuk proses fotosintesis. Namun demikian, kalium tidak banyak diberikan dalam budi daya tambak karena sudah ada suplai dari air laut yang mengandung $\mathrm{K}$ sebesar $420 \mathrm{mg} / \mathrm{L}$ pada salinitas 35 ppt (Riley \& Chester, 1971).

Telah disebutkan sebelumnya bahwa salah satu ciri tanah sulfat masam adalah $\mathrm{pH}$ tanah yang rendah dan kandungan unsur toksik seperti $\mathrm{Fe}$ dan $\mathrm{Al}$ yang tinggi. Untuk meningkatkan $\mathrm{pH}$ tanah dan mengurangi senyawa toksik dapat dilakukan upaya remediasi dan pengapuran. Oleh karena petambak budi daya rumput laut di tanah sulfat masam tidak melakukan upaya remediasi sebelum persiapan tambaknya, menyebabkan kualitas tanah tambak tanah sulfat masam tergolong rendah. Sebagai akibatnya, pengapuran yang diterapkan petambak tanah sulfat masam nyata dapat meningkatkan produksi rumput laut. Setiap penambahan dosis kapur $1 \mathrm{~kg} / \mathrm{ha} / \mathrm{th}$ dapat meningkatkan produksi rumput laut sebesar $20,45 \mathrm{~kg} /$ ha/th. Selain mangandung $\mathrm{Ca}$ ada juga kapur yang mengandung Mg seperti dolomit. Magnesium sangat dibutuhkan oleh khlorofil tanaman termasuk rumput laut

Faktor kondisi tambak yaitu luas tambak dan umur tambak memiliki pengaruh yang sama terhadap produks rumput, yaitu apabila ada peningkatan luas tambak ci umur tambak akan menurunkan produksi rumput laut di tambak tanah sulfat masam. Dari koefisien regresi bagi variabel umur tambak adalah 275,98 yang menunjukkan bahwa pertambahan umur tambak dapat menyebakan penurunan produksi rumput laut. Hal ini menunjukkan bahwa semakin bertambah umur tambak berdampak pada penurunan daya dukung lahan. Seperti terlihat pada Tabel 2 bahwa rata-rata umur tambak yang digunakan untuk budi daya rumput laut di Desa Lamasi Pantai adalah 25 
tahun dan sarana produksi yang digunakan sangat rendah yang tentunya berimplikasi pada penurunan kualitas tanah. Sebagai akibatnya produksi rumput laut juga dapat menurun. Karena umur tambak tidak bisa ditahan dan akan bertambah seiring dengan waktu yang terus berjalan, maka upaya pemulihan kondisi tambak merupakan alternatif yang dapat dilakukan untuk mempertahankan atau meningkatkan kondisi tambak. Pemulihan tambak dapat dilakukan melalui persiapan tambak yang baik sebelum penebaran atau membiarkan tambak istirahat untuk waktu tertentu setelah beberapa siklus produksi. Upaya lain adalah penambahan penggunaan sarana produksi tambak agar suplai unsur hara yang diperlukan oleh rumput laut dapat lebih terjamin

Telah dijelaskan sebelumnya bahwa keberadaan bandeng dalam budi daya rumput laut diharapkan dapat meningkatkan produksi rumput laut, apabila jumlah bandeng yang ditebar tidak bersaing dengan rumput laut dalam hal pemanfaatan relung ekologis. Studi ini menunjukkan bahwa penambahan padat penebaran bandeng yang ada akan menyebabkan penurunan produksi rumput laut. Apabila makanan alami seperti kelekap, lumut maupun epifit sudah tidak tersedia dalam tambak, maka bandeng akan memakan rumput laut terutama talus yang masih muda. Telah banyak dilaporkan bahwa bandeng yang dipolikultur dengan rumput laut sering berbau rumput laut pada saat dikonsumsi. Dalam hal ini, perlu diketahui kombinasi kepadatan yang optimal antara rumput laut dan bandeng dalam sistem polikultur $\mathrm{di}$ tambak tanah sulfat masam. Untuk tambak bukan tanah sulfat masam seperti di Kabupaten Takalar, Kahar (2001) merekomendasikan kepadatan rumput laut $1.000 \mathrm{~kg}$ basah/ha dan padat penebaran bandeng 2.000 ekor/ha dalam polikultur rumput laut dan bandeng

\section{KESIMPULAN DAN SARAN}

Rekayasa (disain, konstruksi, dan tata letak) tambak dan kualitas tanah tambak tanah sulfat masam di Desa Lamasi Pantai masih tergolong rendah. Namun demikian, dengan menebar rumput laut rata-rata $1.499 \mathrm{~kg}$ basah/ha/th dengan metode tebar yang dipolikultur dengan nener bandeng 4.465 ekor/ha/th dan diberi pupuk urea, $\mathrm{KCl}$, dan kapur berturut-turut 40,14 , dan $32 \mathrm{~kg} / \mathrm{ha}$ dapat diperoleh produksi rumput laut $11.275 \mathrm{~kg}$ kering $/ \mathrm{ha} / \mathrm{th}$ setelah dipanen sebanyak 9 kali/tahun.

Dari 11 variabel yang dikaji dalam studi ini menunjukkan bahwa hanya 7 variabel di antaranya yang secara nyata dapat digunakan untuk menentukan produksi rumput laut di tambak tanah sulfat masam adalah berturut-turut dari yang terbesar pengaruhnya yaitu pupuk urea, luas tambak, pengelaman bertambak, pupuk $\mathrm{KCl}$, umur tambak, padat penebaran nener bandeng, dan kapur.

Produktivitas rumput laut di tambak tanah sulfat masam dapat ditingkatkan dengan menambahkan pupuk urea, pupuk $\mathrm{KCl}$, dan kapur, serta memperbanyak pengalaman petambak dan sebaliknya mengurangi luas tambak yang dikelola dan menurunkan padat penebaran nener bandeng serta memulihkan kondisi tambak.

\section{DAFTAR PUSTAKA}

Anonim. 2003a. AS butuh rumput laut Sul-Sel. Fajar, Rabu, 15 Oktober 2003, 5 pp.

Anonim. 2003b. Rumput laut Luwu terbaik di Indonesia. Fajar, Senin, 17 Maret 2003, 16 pp

Daud, R., M.J.R. Yakob, dan Suwardi. 1994. Mutu rumput laut, Gracilaria sp. pada kualitas tanah tambak yang berbeda. Warta Balitdita, 6(2): 8-10.

Draper, N. dan H. Smith. 1992. Analisis Regresi Terapan. Dialihbahasakann oleh: B. Sumantri. Edisi kedua. PT Gramedia Pustaka Utama, Jakarta, $671 \mathrm{pp}$.

Hanafi, A. 1990. Socio-economic and managerial profiles of brackishwater aquaculture in South Sulawesi Jurnal Penelitian Budidaya Pantai, 6(2): 97--114.

Hendrajat, E.A. 2004. Pengaruh perbedaan kedalaman air terhadap pertumbuhan rumput laut, Gracilaria verrucosa di tambak tanah sulfat masam. Balai Riset Perikanan Budidaya Air Payau, Maros, 12 pp.

Kahar. 2001. Kajian metode budidaya rumput laut Gracilaria sp spesifik lokasi di tambak mendukung spaku rumput laut di Sulawesi Selatan. Dalam Saenong, S., Amirullah, A. Bastian, J. Halifah, dan S. Riyadi (Eds.). Prosiding Seminar Regional Hasil-hasil Penelitian/Pengkajian Teknologi Pertanian. Balai Pengkajian Teknologi Pertanian Sulawesi Selatan, Makassar, p. 74-79.

Kuhl, A. 1974. Phosphorus. In Stewart, W.D.P. (Ed.). Algal Physiology and Biochemistry. Botanical Monographs. Volume 10. Blackwell Scientific Publication, Oxford, London, Edinburgh, Melbourne, p. 636-654.

Mubarak, H., S. Ilyas, W. Ismail, I.S. Wahyuni, S.T. Hartati, E. Pratiwi, Z. Jangkaru, dan R. Arifudin. 1990. Petunjuk Teknis Budidaya Rumput Laut. Pusat Penelitian dan Pengembangan Perikanan, Jakarta, $93 \mathrm{pp}$.

Mustafa, A. and J. Sammut. 2003. Characteristics of coastal land in Walenrang Disrict, Indonesia Geography Program, Faculty of the Built Environment, The University of New South Wales, Sydney, $30 \mathrm{pp}$.

Mustafa, A., B. Pantjara, dan Tarunamulia. 2004 Pemanfaatan tambak tanah sulfat masam untuk budidaya. Disampaikan pada "Sarasehan dan Temu Konsultasi Teknologi Pendayagunaan Tambak Tanah Sulfat Masam untuk Budidaya", Luwu, 24 Januari 2004. Balai Riset Perikanan Budidaya Air Payau, Maros, $19 \mathrm{pp}$. 
Noggle, G.R. and G.J. Fritz. 1986. Introduction to Plant Physiology. Second edition. Prentice-Hall of India, Private Ltd., New Delhi.

Padda, H. 1986. Usahatani tambak di Kabupaten Jeneponto, Sulawesi Selatan. Jurnal Penelitian Budidaya Pantai 2(1 \& 2): 174-183.

Pantjara, B., E.A. Hendrajat, Utojo, E. Septianingsih, dan Y. Hala. 2003. Remediasi tanah dasar terhadap peningkatan produksi rumput laut, Gracilaria verrucosa di tambak tanah sulfat masam. Balai Riset Perikanan Budidaya Air Payau, Maros, $21 \mathrm{pp}$.

Rasjid, F., Kahar, A. Tompo, Utojo, dan A. Ismail. 1993. Pengaruh padat penebaran dalam polikultur rumput laut, udang, dan bandeng terhadap produktivitas tambak. Dalam Hanafi, A., M. Atmomarsono, dan S. Ismawati (Eds.). Prosiding Seminar Hasil Penelitian Perikanan Budidaya Pantai. Balai Penelitian Perikanan Budidaya Pantai, Maros, p. $73-78$
Retnowati, N., J.T. Murtini, S. Wibowo, dan Suparno. 1995. Kajian pemasaran dalam menunjang usaha budidaya rumput laut. Dalam Cholik, F., A. Rukyani, A.S. Sarnita, E.S. Heruwati, Suparno, D. Monintja, K. Soewardi, J. Widodo, dan V.P. Nikijuluw (Eds.). Prosiding Simposium Perikanan Indonesia I, Buku Il Bidang: Pascapanen, Sosial Ekonomi, dan Penangkapan. Pusat Penelitian dan Pengembangan Perikanan, Jakarta, p. 289-302.

Riley, J.P. and R. Chester. 1971. Introduction to Marine Chemistry. Academic Press, London, $465 \mathrm{pp}$.

Sadhori, S.N. 1989. Budidaya Rumput Laut. Balai Pustaka, Jakarta, 109 pp.

Sammut, J., A. Mustafa, A. Hanafi, Tarunamulia, and S. Tahe. 2003. Polyculture: extends production life for ponds with acid sulfate soil. Global Aquaculture Advocate, $\mathrm{VI}(3)$ : 72-73.

Sammut, J. and L.K. Rebecca. 2000. An Introduction to Acid Sulfate Soils. Natural Heritage Trust, Australia, 27 pp. 
Lampiran 1. Ringkasan model dalam penentuan faktor pengelolaan yang berpengaruh dalam budi daya rumput laut di tambak tanah sulfat masam

Appendix 1. Model summary to determine management factors that effect in seaweed culture in acid sulfate soils affected ponds

\begin{tabular}{ccccc}
\hline Model & $\mathbf{R}$ & $\mathbf{R}^{2}$ & $\begin{array}{c}\mathbf{R}^{2} \text { yang dikoreksi } \\
\text { Adjusted } \mathbf{R}^{\mathbf{2}}\end{array}$ & $\begin{array}{c}\text { Standar galat estimasi } \\
\text { Error standard of estimate }\end{array}$ \\
\hline 1 & $0.819^{\text {a }}$ & 0.670 & 0.469 & $3,465.43$ \\
2 & $0.819^{\mathrm{b}}$ & 0.670 & 0.497 & $3,373.20$ \\
3 & $0.819^{\mathrm{C}}$ & 0.670 & 0.522 & $3,287.96$ \\
4 & $0.814^{\mathrm{d}}$ & 0.663 & 0.535 & $3,243.69$ \\
5 & $0.805^{\mathrm{e}}$ & 0.649 & 0.537 & $3,236.27$ \\
\hline
\end{tabular}

Keterangan (Note):

a. Prediktor (Predictors): Konstanta (constant), umur petambak (fish farmer age), pendidikan petambak (fish farmer education), pengalaman petambak (fish farmer experience), luas tambak (pond size), umur tambak (pond age), padat penebaran rumput laut (seaweed stocking density), padat penebaran nener bandeng (milkfish fry stocking density), dosis pupuk urea (dosage of urea fertilizer), dosis pupuk $\mathrm{KCl}$ (dosage of $\mathrm{KCl}$ fertilizer), dosis kapur (dosage of lime), frekuensi panen rumput laut (seaweed harvest frequency)

b. Prediktor (Predictors): Konstanta (constant), umur petambak (fish farmer age), pengalaman petambak (fish farmer experience), luas tambak (pond size), umur tambak (pond age), padat penebaran rumput laut (seaweed stocking density), padat penebaran nener bandeng (milkfish fry stocking density), dosis pupuk urea (dosage of urea fertilizer), dosis pupuk $\mathrm{KCl}$ (dosage of $\mathrm{KCl}$ fertilizer), dosis kapur (dosage of lime), frekuensi panen rumput laut (seaweed harvest frequency)

c. Prediktor (Predictors): Konstanta (constant), umur petambak (fish farmer age), pengalaman petambak (fish farmer experience), luas tambak (pond size), umur tambak (pond age), padat penebaran nener bandeng (milkfish fry stocking density), dosis pupuk urea (dosage of urea fertilizer), dosis pupuk $\mathrm{KCl}$ (dosage of $\mathrm{KCl}$ fertilizer), dosis kapur (dosage of lime), frekuensi panen rumput laut (seaweed harvest frequency)

d. Prediktor (Predictors): Konstanta (constant), umur petambak (fish farmer age), pengalaman petambak (fish farmer experience), luas tambak (pond size), umur tambak (pond age), padat penebaran nener bandeng (milkfish fry stocking density), dosis pupuk urea (dosage of urea fertilizer), dosis pupuk $\mathrm{KCl}$ (dosage of $\mathrm{KCl}$ fertilizer), dosis kapur (dosage of lime)

e. Prediktor (Predictors): Konstanta (constant), pengalaman petambak (fish farmer experience), luas tambak (pond size), umur tambak (pond age), padat penebaran nener bandeng (milkfish fry stocking density), dosis pupuk urea (oosage of urea fertilizer), dosis pupuk $\mathrm{KCl}$ (dosage of $\mathrm{KCl}$ fertilizer), dosis kapur (dosage of lime) 
Lampiran 2. Analisis ragam atau Uji F dari faktor pengelolaan dalam budi daya rumput laut di tambak tanah sulfat masam

Appendix 2. Variance analysis or F Test of management factors in seaweed culture in acid sulfate soils affected ponds

\begin{tabular}{|c|c|c|c|c|c|}
\hline Model & $\begin{array}{l}\text { Jumlah kuadrat tengah } \\
\text { Sum of squares }\end{array}$ & $\begin{array}{c}\text { Derajat bebas } \\
\text { Degrees of freedom }\end{array}$ & $\begin{array}{l}\text { Kuadrat tengah } \\
\text { Mean square }\end{array}$ & $\mathrm{F}$ & $P$ \\
\hline $\begin{array}{l}1 \text { Regresi } \\
\text { Regression }\end{array}$ & $439,820,431$ & 11 & $39,983,675.58$ & 3.329 & 0.012 \\
\hline $\begin{array}{l}\text { Sisa } \\
\text { Residual }\end{array}$ & $216,166,177$ & 18 & $12,009,232.07$ & & \\
\hline Total & $655,986,608$ & 29 & & & \\
\hline $\begin{array}{l}2 \text { Regresi } \\
\text { Regression }\end{array}$ & $439,796,145$ & 10 & $43,979,614.47$ & 3.865 & 0.005 \\
\hline $\begin{array}{l}\text { Sisa } \\
\text { Residual }\end{array}$ & $216,190,463$ & 19 & $11,378,445.47$ & & \\
\hline Total & $655,986,608$ & 29 & & & \\
\hline $\begin{array}{l}3 \text { Regresi } \\
\text { Regression }\end{array}$ & $439,772,665$ & 9 & $48,863,629.52$ & 4.520 & 0.002 \\
\hline $\begin{array}{l}\text { Sisa } \\
\text { Residual }\end{array}$ & $216,213,943$ & 20 & $10,810,697.15$ & & \\
\hline Total & $655,986,608$ & 29 & & & \\
\hline $\begin{array}{l}4 \text { Regresi } \\
\text { Regression }\end{array}$ & $435,035,218$ & 8 & $54,379,402.27$ & 5.168 & 0.001 \\
\hline $\begin{array}{l}\text { Sisa } \\
\text { Residual }\end{array}$ & $220,951,390$ & 21 & $10,521,494.79$ & & \\
\hline Total & $655,986,608$ & 29 & & & \\
\hline $\begin{array}{l}5 \text { Regresi } \\
\text { Regression }\end{array}$ & $425,570,452$ & 7 & $60,795.778 .885$ & 5.805 & 0.001 \\
\hline $\begin{array}{l}\text { Sisa } \\
\text { Residual }\end{array}$ & $230,416,156$ & 22 & $10,473,461.67$ & & \\
\hline Total & $655,986,608$ & 29 & & & \\
\hline
\end{tabular}


Lampiran 3. Konstanta dan koefisien regresi pada Model 5 dari faktor pengelolaan dalam budi daya rumput laut di tambak tanah sulfat masam

Appendix 3. Constant and regression coefficient at Model 5 of management factors in seaweed culture in acid sulfate soils affected ponds

\begin{tabular}{|c|c|c|c|}
\hline Model & B & $t$ & $\boldsymbol{P}$ \\
\hline $\begin{array}{l}\text { Konstanta } \\
\text { Constant }\end{array}$ & $14,293.129$ & 5.131 & 0.000 \\
\hline $\begin{array}{l}\text { Dosis pupuk urea } \\
\text { Dosage of urea fertilizer }\end{array}$ & 109.582 & 5.558 & 0.000 \\
\hline $\begin{array}{l}\text { Luas tambak } \\
\text { Pond size }\end{array}$ & $-1,839.795$ & -4.043 & 0.001 \\
\hline $\begin{array}{l}\text { Pengalaman petambak } \\
\text { Fish famer experience }\end{array}$ & 218.263 & 3.635 & 0.001 \\
\hline $\begin{array}{l}\text { Dosis pupuk } \mathrm{KCl} \\
\text { Dosage of } \mathrm{KCl} \text { fertilizer }\end{array}$ & 87.308 & 3.124 & 0.005 \\
\hline $\begin{array}{l}\text { Umur tambak } \\
\text { Pond age }\end{array}$ & -275.985 & -2.736 & 0.012 \\
\hline $\begin{array}{l}\text { Padat penebaran nener bandeng } \\
\text { Milkfish fry stocking density }\end{array}$ & -0.489 & -2.180 & 0.040 \\
\hline $\begin{array}{l}\text { Dosis kapur } \\
\text { Dosage of lime }\end{array}$ & 20.454 & 2.113 & 0.046 \\
\hline
\end{tabular}


